\title{
Corrigendum: A Regional Neural Network Approach to Estimate Water-Column Nutrient Concentrations and Carbonate System Variables in the Mediterranean Sea: CANYON-MED
}

\author{
Marine Fourrier ${ }^{1 *}$, Laurent Coppola ${ }^{1,2}$, Hervé Claustre ${ }^{1}$, Fabrizio D'Ortenzio ${ }^{1}$, \\ Raphaëlle Sauzède ${ }^{2}$ and Jean-Pierre Gattuso ${ }^{1,3}$ \\ ${ }^{1}$ Sorbonne Université, CNRS, Laboratoire d'Océanographie de Villefranche, Villefranche-sur-Mer, France, ${ }^{2}$ Sorbonne \\ Université, CNRS, Institut de la Mer de Villefranche, Villefranche-sur-Mer, France, ${ }^{3}$ Institute for Sustainable Development and \\ International Relations, Sciences Po, Paris, France
}

Keywords: nutrients, carbonate system, Mediterranean Sea, neural network, CANYON

\section{A Corrigendum on}

\section{OPEN ACCESS}

Edited and reviewed by: Ananda Pascual, Mediterranean Institute for Advanced

Studies (IMEDEA), Spain

*Correspondence: Marine Fourrier

marine.fourrier@obs-vlfr.fr

Specialty section:

This article was submitted to

Ocean Observation,

a section of the journal

Frontiers in Marine Science

Received: 07 January 2021 Accepted: 14 January 2021 Published: 25 January 2021

Citation:

Fourrier M, Coppola L, Claustre H,

$D$ 'Ortenzio $F$, Sauzède $R$ and Gattuso J-P (2021) Corrigendum: A Regional Neural Network Approach to

Estimate Water-Column Nutrient

Concentrations and Carbonate System Variables in the Mediterranean

Sea: CANYON-MED.

Front. Mar. Sci. 8:650509.

doi: 10.3389/fmars.2021.650509
A Regional Neural Network Approach to Estimate Water-Column Nutrient Concentrations and Carbonate System Variables in the Mediterranean Sea: CANYON-MED

by Fourrier, M., Coppola, L., Claustre, H., D'Ortenzio, F., Sauzède, R., and Gattuso, J.-P. (2020). Front. Mar. Sci. 7:620. doi: 10.3389/fmars.2020.00620

In the original article, there was an error. The published version of the neural network created a fake seasonality in the output parameters at depth. This has been corrected and a second version of the CANYON-MED neural networks was created.

A correction has been made to the Abstract:

A regional neural network-based method, "CANYON-MED" is developed to estimate nutrients and carbonate system variables specifically in the Mediterranean Sea over the water column from pressure, temperature, salinity, and oxygen together with geolocation and date of sampling. Six neural network ensembles were developed, one for each variable (i.e., three macronutrients: nitrates $\left(\mathrm{NO}_{3}^{-}\right)$, phosphates $\left(\mathrm{PO}_{4}^{3-}\right)$ and silicates $\left(\mathrm{Si}(\mathrm{OH})_{4}\right)$, and three carbonate system variables: $\mathrm{pH}$ on the total scale $\left(\mathrm{pH}_{\mathrm{T}}\right)$, total alkalinity $\left(A_{\mathrm{T}}\right)$, and dissolved inorganic carbon or total carbon $\left(C_{\mathrm{T}}\right)$, trained using a specific quality-controlled dataset of reference "bottle" data in the Mediterranean Sea. This dataset is representative of the peculiar conditions of this semi-enclosed sea, as opposed to the global ocean. For each variable, the neural networks were trained on $80 \%$ of the data chosen randomly and validated using the remaining 20\%. CANYON-MED retrieved the variables with good accuracies (Root Mean Squared Error): $0.78 \mu \mathrm{mol} . \mathrm{kg}^{-1}$ for $\mathrm{NO}_{3}^{-}, 0.043 \mu \mathrm{mol} . \mathrm{kg}^{-1}$ for $\mathrm{PO}_{4}^{3-}$ and $0.71 \mu \mathrm{mol} . \mathrm{kg}^{-1}$ for $\mathrm{Si}(\mathrm{OH})_{4}, 0.014$ units for $\mathrm{pH}_{\mathrm{T}}, 13 \mu \mathrm{mol} . \mathrm{kg}^{-1}$ for $A_{\mathrm{T}}$ and 12 $\mu$ mol. $\mathrm{kg}^{-1}$ for $C_{\mathrm{T}}$. A second validation on the ANTARES independent time series confirmed the method's applicability in the Mediterranean Sea. After comparison to other existing methods to estimate nutrients and carbonate system variables, CANYON-MED stood out as the most robust, using the aforementioned inputs. The application of CANYON-MED on the Mediterranean Sea data from autonomous observing systems (integrated network of Biogeochemical-Argo floats, Eulerian moorings and ocean gliders measuring hydrological properties together with oxygen 
concentration) could have a wide range of applications. These include data quality control or filling gaps in time series, as well as biogeochemical data assimilation and/or the initialization and validation of regional biogeochemical models still lacking crucial reference data. Matlab and $\mathrm{R}$ code are available at https://github. com/MarineFou/CANYON-MED/v2/.

A correction has been made to Material and methods, ANN ensemble model, Paragraph 1:

The robustness and reliability of an ANN can be significantly improved by combining several ANNs into an ANN ensemble model (Sharkey, 1999; Linares-Rodriguez et al., 2013). The construction of an ANN ensemble is done in two main steps. First, the individual members of the model are created (as described above in section "Multi-Layered Perceptron"). Second, the combination of the outputs of these members is averaged to obtain the unique ensemble output. Thus, for each neural network $\left[\mathrm{NO}_{3}^{-}, \mathrm{PO}_{4}^{3-}, \mathrm{Si}(\mathrm{OH})_{4}, A_{\mathrm{T}}, C_{\mathrm{T}}, \mathrm{pH}_{\mathrm{T}}\right]$, the ten best topologies were chosen according to their statistics (as defined in section "Validation Statistics Metrics"). The final output of each neural network ensemble model (ANN-E) corresponds to the mean of the outputs of these ten best ANNs (if falling less than a standard deviation from the mean). Additionally, the best topology (ANN-1) among the ten best was also selected to compare between a one ANN structure and a neural network ensemble.

A correction has been made to Material and methods, CANYON-MED, Paragraph 1:

Based on the CANYON networks (Sauzède et al., 2017) principle, the CANYON-MED neural networks corresponding to neural-network ensemble models (ANN-E) (as described in "ANN Ensemble Model”) were developed. Similarly to the work

\section{REFERENCES}

Béthoux, J. P., Morin, P., Chaumery, C., Connan, O., Gentili, B., and Ruiz-Pino, D. (1998). Nutrients in the Mediterranean Sea, mass balance and statistical analysis of concentrations with respect to environmental change. Mar. Chem. 63, 155-169. doi: 10.1016/S0304-4203(98)00059-50

Béthoux, J. P., Morin, P., and Ruiz-Pino, D. P. (2002). Temporal trends in nutrient ratios: chemical evidence of Mediterranean ecosystem changes driven by human activity. Deep Sea Res. Part II Top. Stud. Oceanogr. 49, 2007-2016. doi: 10.1016/S0967-0645(02)00024-23

Borghini, M., Bryden, H., Schroeder, K., Sparnocchia, S., and Vetrano, A. (2014). The Mediterranean is becoming saltier. Ocean Sci. 10, 693-700. doi: 10.5194/os-10-693-2014

Linares-Rodriguez, A., Ruiz-Arias, J. A., Pozo-Vazquez, D., and Tovar-Pescador, J. (2013). An artificial neural network ensemble model for estimating global solar radiation from Meteosat satellite images. Energy 61, 636-645. doi: 10.1016/j.energy.2013.09.008 by Sauzède et al. (2017), the chosen input variables for the networks are in situ measurements of pressure, temperature, salinity (water mass characteristics), and oxygen together with geolocation (latitude and longitude) and date of sampling. Compared to the CANYON networks, where the year is an input only for $\mathrm{pH}_{\mathrm{T}}$ and $C_{\mathrm{T}}$, the decimal year has been chosen as an input for the six CANYON-MED networks [i.e., $\mathrm{NO}_{3}^{-}$, $\mathrm{PO}_{4}^{3-}, \mathrm{Si}(\mathrm{OH})_{4}, A_{\mathrm{T}}, C_{\mathrm{T}}$ and $\left.\mathrm{pH}_{\mathrm{T}}\right]$. This change, namely the transformation from day of year and year to decimal year for each network, was based on the long-term increases in deep nutrients observed in the western basin by Béthoux et al. (1998, 2002), as well as the increases in temperature and salinity in the deep Mediterranean Sea over the past 40 years (Borghini et al., 2014) which demonstrate the need of a temporal component in CANYON-MED networks.

A correction has been made to Material and methods, CANYON-MED, Paragraph 3: the following text has been removed.

"Furthermore, in agreement with the CANYON networks, the doy has been modified to account for the periodicity of this measurement [doy 365 (end of December) of a year is similar to doy 1 (beginning of January) of the next year from a chronological perspective]. It was therefore transformed into radians according to:

$$
d o y_{r a d}=\frac{d o y^{*} \pi^{\prime \prime}}{\frac{365}{2}}
$$

The authors apologize for this error and state that this does not change the scientific conclusions of the article in any way. The original article has been updated.

Sauzède, R., Bittig, H. C., Claustre, H., Pasqueron de Fommervault, O., Gattuso, J.-P., Legendre, L., et al. (2017). Estimates of water-column nutrient concentrations and carbonate system parameters in the global ocean: a novel approach based on neural networks. Front. Mar. Sci. 4:128. doi: 10.3389/fmars.2017.0 0128

Sharkey, A. J. C. (ed.) (1999). Combining Artificial Neural Nets: Ensemble and Modular Multi-Net Systems. Berlin: Springer.

Copyright (c) 2021 Fourrier, Coppola, Claustre, D’Ortenzio, Sauzède and Gattuso. This is an open-access article distributed under the terms of the Creative Commons Attribution License (CC BY). The use, distribution or reproduction in other forums is permitted, provided the original author(s) and the copyright owner(s) are credited and that the original publication in this journal is cited, in accordance with accepted academic practice. No use, distribution or reproduction is permitted which does not comply with these terms. 